\title{
Sliding wear studies of microwave clad versus unclad surface of stainless steel 304
}

\author{
Akshata M. K..$^{1^{*}}$, Ajit M. Hebbale ${ }^{1}$, and Srinath M. S. ${ }^{1}$ \\ ${ }^{1}$ Department of Mechanical Engineering, NMAM Institute of Technology, Nitte. 574110, India
}

\begin{abstract}
Small and large scale (gas power plant, hydro power plant), automobile industries are suffering by failure of component. Sometimes, it is also observed that the component which was failed due to these reasons are very much costly and replacement of those also very difficult due to the complex geometry. By using Microwave hybrid heating, WC-12Co based clads were developed on austenitic stainless steel (SS304). Microwave clads were developed by introducing the preplaced, preheated powder for a duration of $15 \mathrm{~min}$ to microwave radiation at $2.45 \mathrm{GHz}$ frequency and $900 \mathrm{~W}$ power in domestic microwave applicator. By using optical microscope and scanning electron microscope (SEM), the developed clads were characterized. By using pin-on-disk, wear performance of the WC-12Co based clads and unclad samples were tested. It is observed that developed clad samples performed superior wear resistance than unclad samples.
\end{abstract}

Keywords: Microwave, Cladding, SEM, Wear, Austenitic Stainless Steel

\section{Introduction}

Austenitic Stainless steel has superior wear and erosion unsusceptible in several environments and has been broadly used in variety of sectors of industries. Generally, components of stainless steel fail more frequently due to erode instead of corrosion related problems. Hence, it is very much essential to modify the surface of the components to improve the service life of the component. Wear, corrosion and tear of the component surface are the main reason for the failure of the engineering materials [1-4]. It is comprehensively not verbalized in potential wear applications. However, to reach an increased functional surface of the steel can be a conceivable arrangement in many conditions. Bloyce [5] reported surface alloying is the best solution to decrease the wear rate. Now days various methods like cyaniding, carburizing, nitriding, and cladding techniques are available to improve the surface properties. Cladding, generally a popularly used technique to enhance the surface property of the intend material by fully changing the phase from solid to liquid of clad powder particles along with partial melting of the substrate. In laser cladding the laser beam melts the clad particles as well substrate and forms enough engineering thickness with fine metallurgical bond with substrate [6].

The accomplished review of material development through microwave energy and sintering of ceramics includes aluminum, zirconium oxide, barium titanium, and WC-Co based ceramic metal composites are reported[7]. Oghbaei et al. [8] reported the theory of microwaves and usage in different areas of manufacturing system. Authors extended his work to composites, polymers, and metallic powders. The detailed investigation of sliding wear studies was done on $\mathrm{WC} 10 \mathrm{Co} 2 \mathrm{Ni}$. For lower sliding speed these has shown better

\footnotetext{
*Corresponding author: akshatha_213@nitte.edu.in
} 
wear resistance [9]. Sharma et al. [10] described the joining of material through domestic microwave oven. Srinath et al. [11] Researches bonding of copper in mass form within short duration through microwave energy and it was noted that consistent microstructure secured the uniform volumetric heating all around the weld region. An organized layer of SS-316 and MS was formed by the authors when implemented microwave joining of different metals with Ni based powder [12]. Badiger et al. reported [13] Inconel-625 alloy was weld through microwaves using $\mathrm{Ni}$ based powder. Cobalt based clad are created through microwave vitality on martensitic stainless steel (AISI-420). The developed clad shown excellent metallurgical bond with $132 \%$ of higher wear resistance than the unclad surface. The cobalt based clad are also formed to be having superior erosion wear resistant $[14,15]$.Very recently, many researcher explored the cladding process through microwave energy. The innovation of this microwave cladding has confirmed that the developed clad has least amount of porosity and least defect as well crack free structures. This crack free structure leads to perform developed mechanical properties of material surface which is under analysis. It was discovered that the enhancement of clad surface through microwave energy has immense impact on material development cost and also involves minimal time and energy [16-18].

The current study investigate, the possibility of using domestic microwave oven for development of WC-12Co based clad on steel SS304. Dry sliding wear studies were carried out on developed clads and finally analyzed through SEM.

\section{Experimental Details}

\subsection{Materials and Microwave Cladding process}

A domestic microwave oven having microwave energy was used in this work are the well familiar commercially available hard facing alloying of WC-12Co based powder having particle size of $35 \mu \mathrm{m}$ has been used to improve the surface SS304 steel. Typical SEM image of substrate SS304 is depicted in Fig.1.

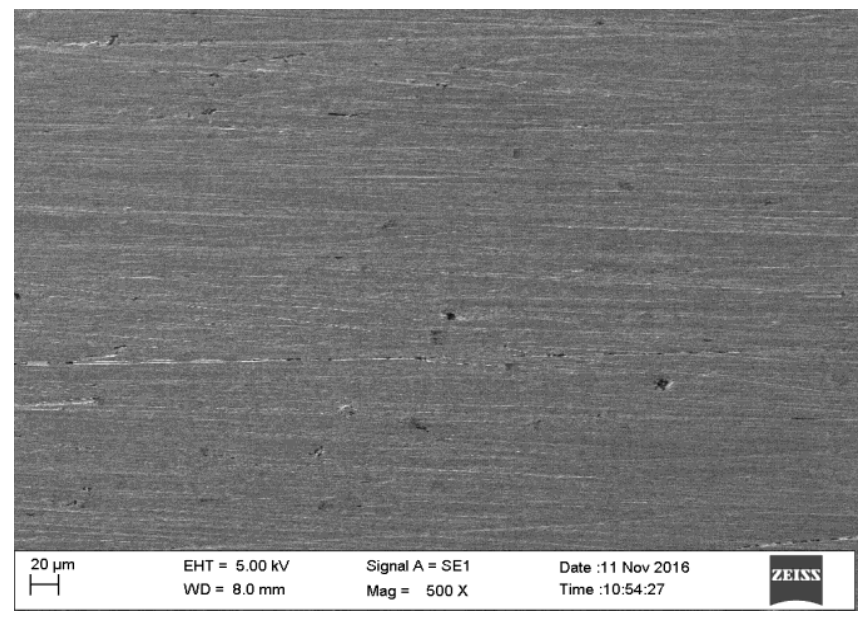

Fig. 1. Morphology structure of SS304. 
The desirable samples are sliced to a size of $12 \times 12 \times 5 \mathrm{~mm}^{3}$ from SS304 steel plate. Prior to the operation, samples are polished to remove any possible impurities such as grit and oil. Further, in a microwave oven the clad powder was heated in advance at approximately $100^{\circ}-120^{\circ} \mathrm{C}$ for $1 \mathrm{~h}$. By conserving a mean thickness of about $1 \mathrm{~mm}$, the clad powder was preplaced physically on the substrate. The preplaced clad powder was melted and that leads to strong metallic bond between the substrate. In the current work charcoal powder was used to gain the range of temperature powder particles. To avoid the adulteration of clad powder with charcoal powder, a precise flat graphite sheet is used as a barrier. Inside a refractory insulating box, the entire arrangement was kept as appeared in the Fig.2. It is noticed that the microwave cladding process effectively depends on the subjected time of microwaves.

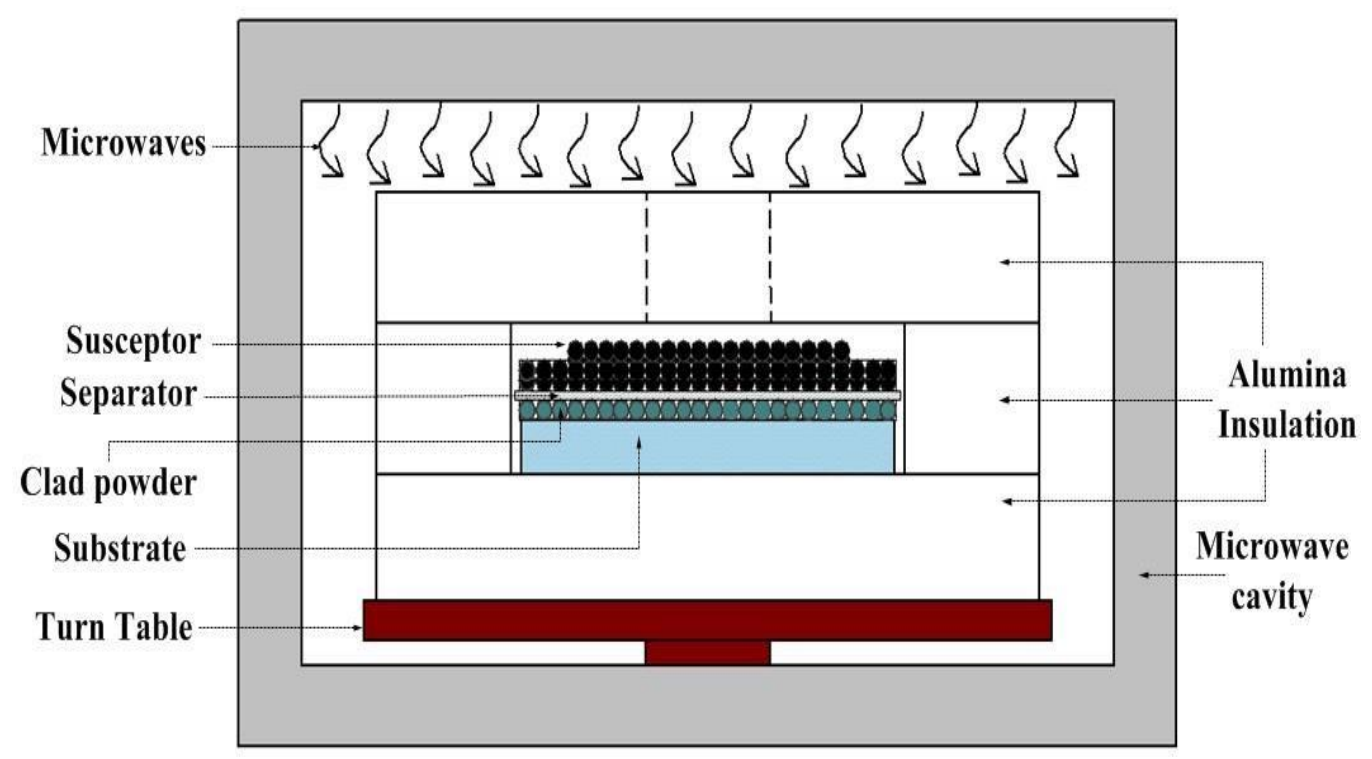

Fig. 2. Schematic of experimental setup of microwave cladding process [21].

\subsection{Dry sliding wear studies}

Pin on disc wear test is done to calculate the amount of wear rate on the surface of developed clad and unclad surface of S S304. A dry sliding wear execution of the created clad surface was assessed through pin on dics tribometer (Make: Ducom India) under different loading conditions. The sample size of $12 \times 12 \times 5 \mathrm{~mm}^{3}$ were machined of developed clad surface. The $10 \mathrm{~mm}$ diameter steel pins were welded to the opposite side of the developed surface to make easy to fix to the fixture. Finally the developed samples were polished through \#1000 grit Sic paper to preserve a consistent surface contact. To gauge the wear rate of the pins before the test and after the test a microelectronic weight balance was used. Finally, the typical load was applied on the created clad surface through lever, string and pulley setup. The schematic of exploratory setup utilized as a part of the present work is appeared in Fig. 3. 


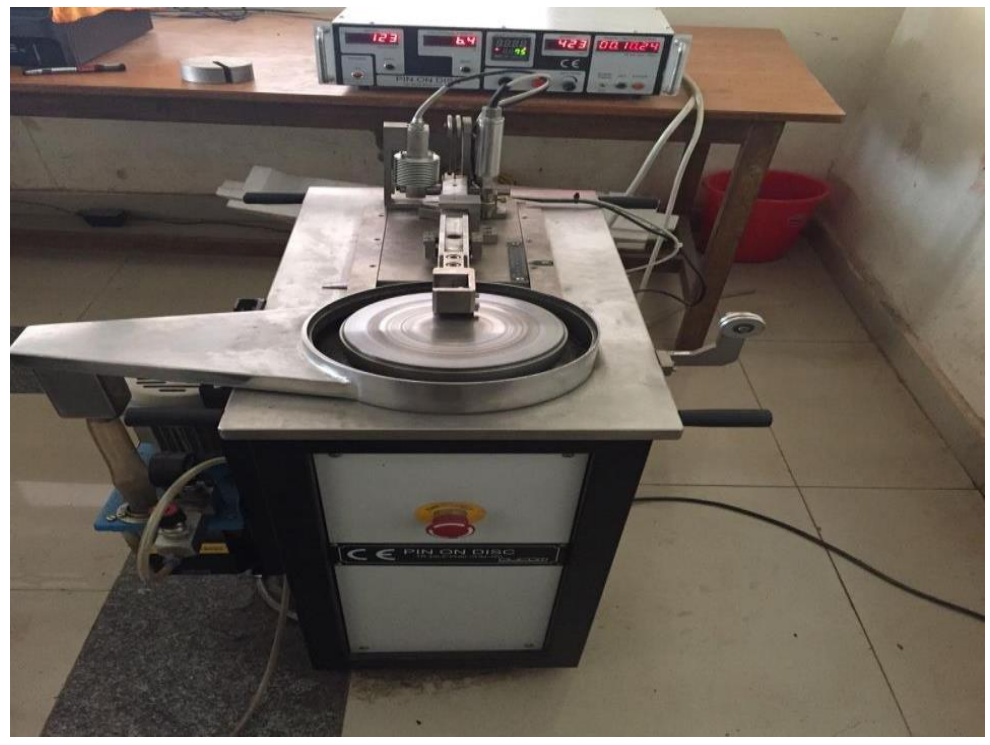

Fig. 3. Schematic Pin on disc arrangement.

\section{Results and Discussions}

The wear studies of WC-12Co based developed clad surface was analysed through SEM to determine the sliding effect on the clad surface.

\subsection{Microscopic inspection of worn surface}

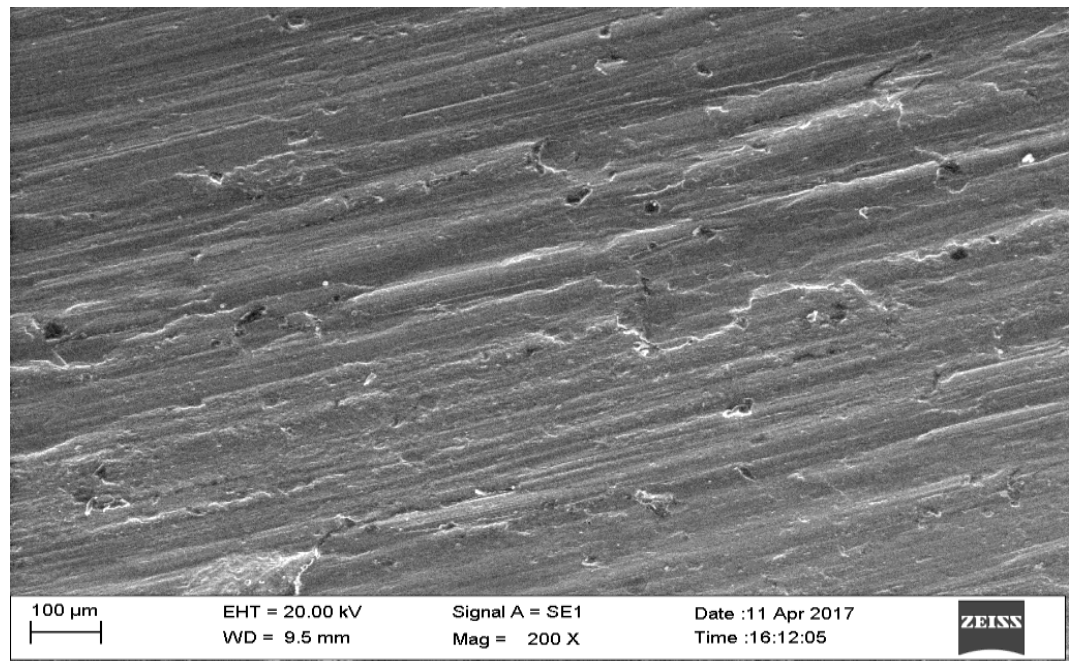

Fig 4. Typical SEM analysis of the worn surface of WC-12Co microwave clad at $20 \mathrm{~N}$ loads.

The WC-12Co based developed clads surface are subjected to dry sliding wear studies as per L9 Taguchi orthogonal array. The orthogonal L9 array of both the worn rate of clad 
and unclad surface is tabulated in Table 1. The worn surface was observed through scanning electronic microscope. At low loads a imperceptible wear in the form of abrasion and adhesion was noticed. However, comparatively smooth wear tracks and small amount material loss (wear rate) from the contact surface could be observed from Table.1.

Figure 4 shows shallow wear grooves, these are clear indication for the low wear rate on the developed surface than the unclad surface. At higher load $(40 \mathrm{~N})$, the worn surface of exhibits the confirmation of carbide pullouts. These carbide pullouts are established by the occurrence of indentation on the worn surface is shown in Fig.5.

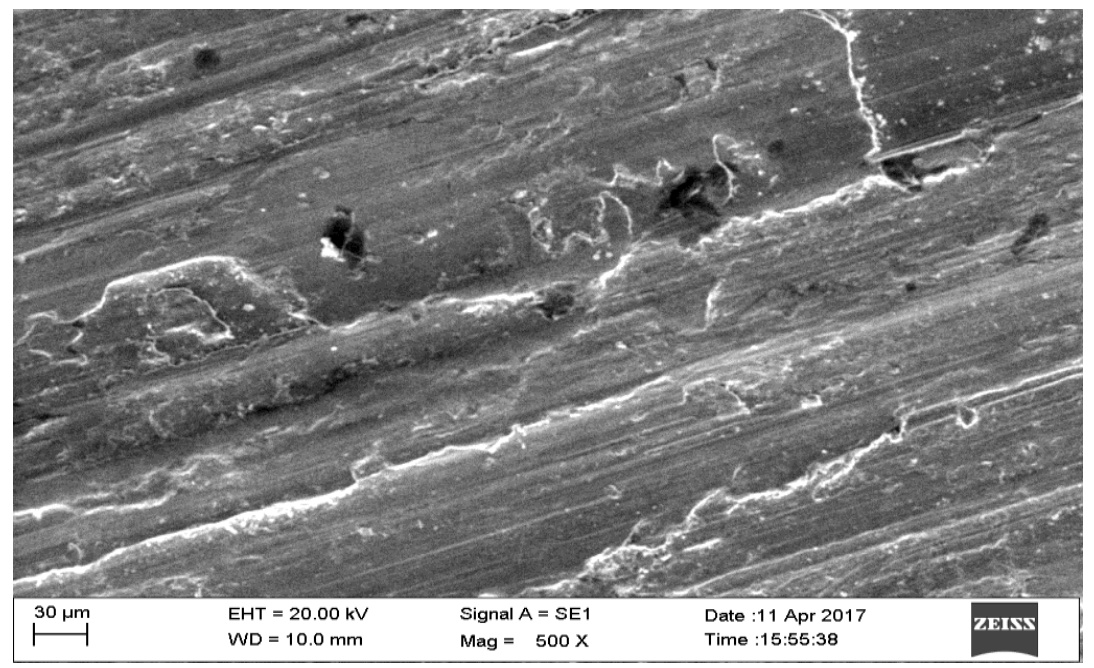

Fig. 5. Typical SEM analysis of the uneven surface of WC-12Co microwave clad at $30 \mathrm{~N}$ loads.

It was discovered that the material removed from unclad surface was more than the developed clad surface. The wear rate of clad surface is minimal when contrasted with unclad surface. The wear rate of clad surface is $0.001 \mathrm{~g}$ where as unclad surface is $0.043 \mathrm{~g}$ as listed in Table.1. At higher load $(40 \mathrm{~N})$ the transfer of material occurs between the clad surfaces to the counter face. The maximum wear took place for higher load $0.156 \mathrm{~g}$ on unclad surface as compared to developed clad surface.

Table 1.Dry sliding wear results of clad and unclad surface.

\begin{tabular}{|l|l|l|l|l|l|}
\hline SNO & $\begin{array}{l}\text { Sliding } \\
\text { Distance(m) }\end{array}$ & $\begin{array}{l}\text { Sliding } \\
\text { Speed } \\
(\mathbf{m} / \mathbf{s})\end{array}$ & $\begin{array}{l}\text { Load } \\
(\mathbf{N})\end{array}$ & $\begin{array}{l}\text { Wear rate of Wear rate of clad } \\
\text { unclad surface } \\
(\mathbf{g})\end{array}$ \\
\hline 1 & 1000 & 4 & 30 & 0.043 & 0.001 \\
surface \\
$(\mathbf{g})$
\end{tabular}




\begin{tabular}{|l|l|l|l|l|l|}
\hline 5 & 2000 & 6 & 20 & 0.036 & 0.031 \\
\hline 6 & 3000 & 2 & 40 & 0.272 & 0.256 \\
\hline 7 & 3000 & 4 & 20 & 0.216 & 0.191 \\
\hline 8 & 3000 & 6 & 30 & 0.156 & 0.153 \\
\hline
\end{tabular}

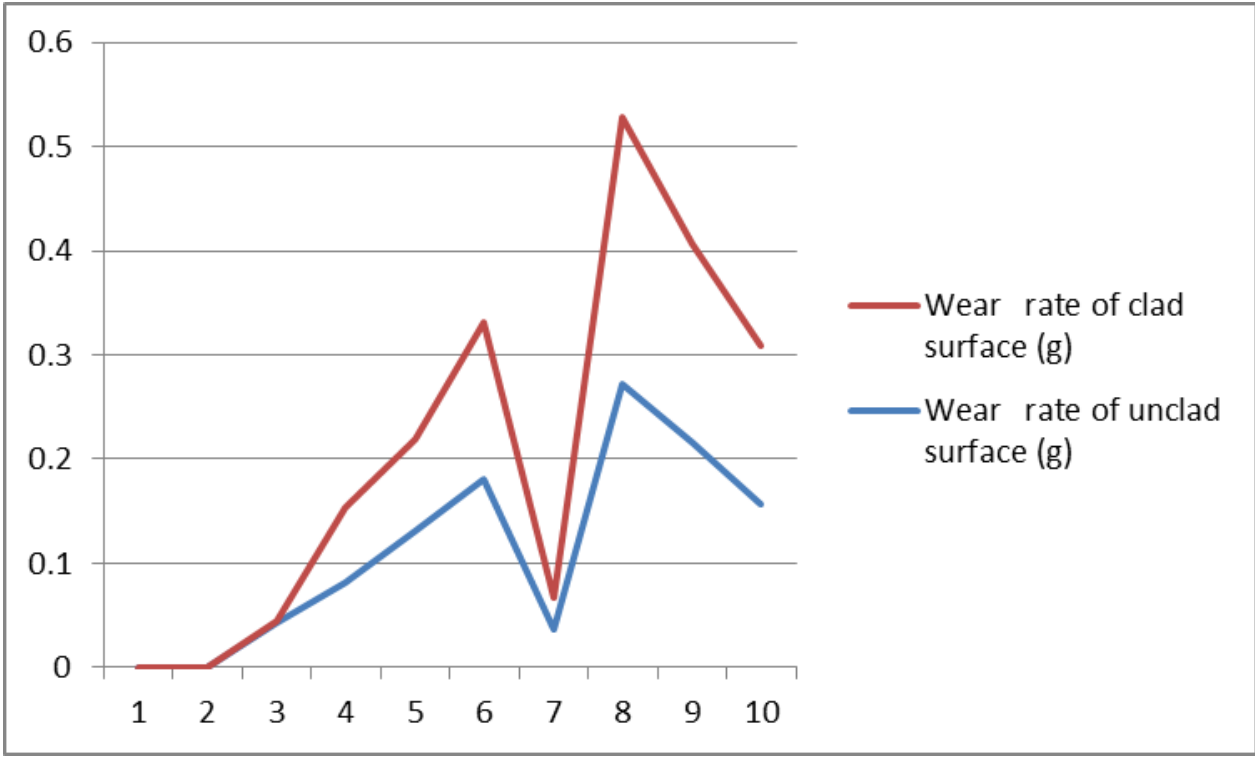

Fig. 6. Analysis of eear rate of clad versus unclad

\section{Conclusions}

Material processing through microwave energy on the metallic substrate has been demonstrated successfully. The current work highlights the improvement of clad surface developed through microwave energy. Metallurgical and mechanical characterization were carried out for developed clads. The few general observations are listed as follows.

-WC-12Co based clads are developed on SS-304 through microwave energy.

-The created clad shows great metallurgical fusion between substrate.

- As received SS304 samples and WC-12Co based developed clads surface are subjected to pin on disc wear studies.

-Taguchi orthogonal array is successfully used to conduct the wear studies.

-The worn surface was observed through SEM. At lower loads a imperceptible wear in the form of abrasion and adhesion was noticed.

- The wear rate of clad surface $(0.001 \mathrm{~g})$ is less as compared to unclad surface $(0.043 \mathrm{~g})$.

-At higher load $(40 \mathrm{~N})$ the transfer of material occurs between the clad surfaces to the counter face. The maximum wear took place for higher load $0.156 \mathrm{~g}$ on unclad surface as compared to developed clad surface. 
-The observation of experimental study proved that the developed clad shown better wear resistant than the as received substrate.

\section{References}

1. Jiang, W.H.; Yao, X.D.; H R Guan, H.R.; Hu, Z.Q. Secondary Carbide Precipitation in a Directionally Solidification Cobalt-base Super alloy. (Metallurgical and Materials Transactions 1999), 30A, 513-520.

2. Shuangjie Chu.; Jianguo Li.; Zhongyuan Liu .On Morphologies, Micro segregation and Mechanical behavior cooling Rate. (Metallurgical and Materials Transactions 1994), 25A, 637-642.

3. Selvan J.S.; Subramanian, K.; Nath, A.K. Effect of laser surface hardening on En18 (AISI 5135) steel. Journal of Material Process Technology (1999), 91, 29-36.

4. Sun, Y.; Bell, T.; Dry sliding wear resistance of low temperature plasma carburized austenitic stainless steel. Wear 2002, 253,689-693.

5. Bloyce A. Surface engineering of titanium alloys for wear protection. Proceeding of IMechE Journal, Journal of Engineering Tribology (1998), 212,467-476.

6. Lin, W.C.; Chen, C. Characteristic of thin surface layer of cobalt-based alloy deposited by laser cladding. Surface and coating technology (2006), 200, 4557-4563.

7. Agrawal, D. Latest global developments in microwave materials processing. (Materials Research Innovations 2010), 14, 3-8.

8. Oghbaei, M.; Mirzaee, O. Microwave versus conventional sintering: a review of fundamentals, advantages and applications. Journal of Alloys and Compounds (2010), 494, 175-189.

9. Gupta, D.; Sharma, A.K. Investigation on sliding wear performance of WC10Co2Ni cladding developed through microwave irradiation. Wear (2011), 271, 1642- 1650.

10. Sharma, A.K.; Srinath, M.S.; Pradeep, K. Microwave Joining of Metallic Materials. Indian Patent (2009). Application No. 1994/Del/2009.

11. Srinath, M.S.; Sharma, A.K.; Kumar, p. A new approach to joining of bulk copper using microwave energy. (Materials and Design 2011), 32, 2685-2694.

12. Srinath. M.S.; Sharma. A. K.; Kumar. P. Investigation on microstructural and mechanical properties of microwave processed dissimilar joints. (Journal of Manufacturing Process 2011), 13,141-146.

13. Ravindra I. Badigera.; Narendranath. S.; Srinath. M.S. Joining of Inconel-625 alloy through microwave hybrid heating and its characterization. (Journal of Manufacturing Process 2015), 18,117-123.

14. A M Hebbale.; Srinath M S.; Microstructural Studies of Cobalt Based Microwave Clad Developed on Martensitic Stainless Steel (AISI-420). Trans Indian Inst Met DOI 10.1007/s12666-017-1206-7.

15. A M Hebbale.; Srinath M S.; Taguchi analysis on erosive wear behaviour of cobalt based microwave cladding on stainless steel AISI-420. Measurement 99 (2017) 98-107.

16. Srinath M S.; A M Hebbale.; Microstructural investigation of nickel based cladding developed on austenitic SS304 through microwave irradiation. Journal of materials research and technology. 5(4) (2016) 293-301.

17. A M Hebbale.; Srinath M S.; Microstructure and experimental design analysis of nickel based clad developed through microwave energy. Journal of Perspectives in Science. 8 (2016) 257-259.

18. Srinath M S.; A M Hebbale.; Fuzzy prediction of slurry erosive behavior of cobalt based clad developed through microwave energy. Materials Today: Proceedings 4 (2017) 1804-1811. 